\title{
Exclusion from Healthcare Services and the Emergence of New Stakeholders and Vulnerable Groups in Times of Economic Crisis: A Civil Society's Perspective in Greece
}

\author{
Maria Zafiropoulou ${ }^{2 *}$ \\ ${ }^{1}$ European Commission, Expert "Healthcare and Social Sector" \\ 2 Open University of Cyprus, Nicosia, Cyprus
}

KEYWORDS

Economic crisis

Exclusion

Healthcare

NGOs

Vulnerable groups

\begin{abstract}
The exclusion from access to basic health services, medical examinations, hospital and pharmaceutical care has affected a large number of Greek citizens during the economic crisis. The first aim of this paper is to focus on the analysis of those new vulnerable groups who face access problems to healthcare services. The second aim of the paper is to examine the new stakeholders and to explore the civil society's emerging initiatives.

Unfortunately, so far, there have been only a few cross national surveys that analyze and identify new vulnerable groups, new stakeholders and problems of access to healthcare services in times of crisis. This problem is related to the lack of information and data available for these specific groups even during periods of economic florescence. In order to resolve the problem of data, this paper is based on two large scale European projects in Greece during the latest years of the crisis: the Eurofound research project on 'Access to healthcare in times of crisis' (2013-2014) and the ongoing Fragmex 'Fragmentation and Exclusion: Understanding and Overcoming the multiple impacts of European crisis' research project (2013-2015) using a multi-method approach combining macro and micro perspectives from respectively quantitative official national and international data and qualitative data based on interviews of NGOs and ecclesiastic organizations. The alternative model of civil society's empowerment has not only become one of the most visible symptoms of the crisis but presents, as well, a conceptual construct that attempts to place citizens' synergies in a central place, in a space that emphasizes inter-relationships too often ignored by policymakers.
\end{abstract}

* Contact address: marozafir@gmail.com (M. Zafiropoulou) 


\section{Introduction}

In 2010, the Greek economy entered a deep, structural and multi-faceted crisis, the main features of which are a large fiscal deficit, huge public debt and the continuous erosion of the country's competitive position. A major consequence caused by an economic crisis is social exclusion. This phenomenon is observed mostly in periods when an economic crisis is in exacerbation. Social changes created by the economic recession have had a harsh impact on the healthcare sector with regards to the vulnerability of the populations but also to the active participation of civil society in this sector. In this context, the Greek Equality Ombudsman is asked to step up and outreach population groups in order to imprint institutional problems and highlight citizen dissatisfaction. His last reports of 2012 and 2013 expressed concerns about discrimination in the healthcare, education and social services access, not towards migrants, as usual, but also unemployed persons, people with disabilities and especially senior citizens. Access to services for these groups, according to the report, has recently become even worse than it is for the rest of the population. The first aim of this paper is to focus on the analysis of those new vulnerable groups who face access problems to healthcare services. Indeed, the lack of access to basic health services, medical examinations, hospital and pharmaceutical care has affected a large number of Greek citizens.

In response to these problems, localism and alternative civil society's stakeholders become more engaged during crises (NGOs and religious organizations). Their presence in response to a crisis is often vital for society as these new civil society's initiatives can either retain access where the State cannot do it anymore, find new niches of vulnerable persons not covered till now from public services or create synergies essential for the empowerment of local populations. Consequently, the second aim of the paper is to examine the new stakeholders and to explore the civil society's emerging initiatives.

Unfortunately, so far, there have been only a few cross national surveys that analyze and identify new vulnerable groups, new stakeholders 
and problems of access to healthcare services in times of crisis. This problem is related to the lack of information and data available for these specific groups even during periods of economic florescence. In order to resolve the problem of data, this paper is based on two large scale European projects in Greece during the latest years of the crisis: the Eurofound research project on 'Access to healthcare in times of crisis' (2013-2014) and the ongoing Fragmex 'Fragmentation and Exclusion: Understanding and Overcoming the multiple impacts of European crisis' research project (2013-2015).

The Eurofound country report is based on the national literature, press, administrative national and European databases, 53 interviews with policy makers and NGOs decision makers - conducted in 2013 - and has included four extensive case studies concerning healthcare service providers that were impacted by the crisis and some of their mitigating measures. The interviews, conducted in the winter of 2013, have been analyzed by SPSS statistical package and by NVivo software. It is the first large scale research in Greece which focuses on the impact of the crisis on healthcare overall and in particular, on access for groups in vulnerable situations. This multimethod approach combining macro-level perspectives from quantitative data, informed opinions of key stakeholders illustrating interpretation of results in national contexts, and more micro-perspectives about the real-life impact of the crisis in case studies (Eurofound 2014) is combined in this paper with the methodology of the FRAGMEX project.

Concerning the Fragmex project the initial sample consisted of 45 NGOs of Patras and of 138 NGOs of Athens categorized into groups according to the sectors of their action (Solidarity, Education, Society, Environment, Culture, Multiple Activities, and Health). In total, 67 NGOs were randomly selected by using appropriate algorithms and avoiding selection scenarios like 'selection of the first four NGOs of each group after having ordered them alphabetically'. The interviews conducted in the spring of 2014 were based on the same questionnaire - with some variations. This European project is the first project that applies ontology in social sciences and narrative data. An OPC (Opinions about the Phenomenon of Crisis) 
Ontology - built for the purpose of FragMex - based on the methodological guidelines explained in the DILIGENT methodology (Distributed, Looselycontrolled and evolving Engineering of ONTologies) has been constructed. The proposed ontology, containing 26 classes, 20 relations and 560 instances, ought to represent the relevant concepts reflecting the opinions of the NGOs' representatives about crisis, poverty, social exclusion and counterstrategies implemented during the period of crisis. Thus it was used as a foundation in order to discover new interpretation patterns of these phenomena.

According to ontology's findings, all the problems of social exclusion described by interviewees, in reality, focus on one: the problem of access (access to employment, healthcare and social services, education, access to society and finally even access to the ability of covering basic human needs). Interviewees claim that exclusion from work and unemployment is the most common type of social exclusion (about 40\%). Exclusion from health and medical treatment is very common too. According to the interviewees, this type of exclusion is the second most common, reaching the number of $30 \%$. In this paper we will discuss on the type of exclusion from access to healthcare sector.

Maslow (1943) argued that humans must meet basic physical needs (hunger, sleep, safety) in order to be able to meet emotional needs (belongingness, love, social relationships) and then meet 'higher' needs (self esteem and self actualization). According to his theory, people are motivated by deficiencies in their basic needs. Basic needs such as food, sleep and warmth have to be satisfied in order to survive. Then higher order needs need to be satisfied and so on. However, in crisis, people do not act logically. Some persons feel they are slipping and feel they need to be better taken care of. Others really need help in order to survive. It's important for the State and the NGOs to communicate adequately to this part of the population and address the more basic human needs in Maslow's famous hierarchy. Basic biological and physiological needs constitute the immediate necessity without compromising the next level (safety, property, family). Being able to 
provide people with information about stressful situations -such as those provided by NGOs- can sometimes support them to handle the challenges they face.

In this research, Maslow's theory will be combined with classical theories of social exclusion as conceived by Silver (1994), Byrne (1999) and Fischer (2011), i.e. in relation to the standard of leaving in a society as a

whole. Following the same doctrinal pathway, the European Parliament $(2014,1)$ refers to social exclusion as a danger for Europe's democracies and defines it as 'the exclusion of certain people from participating fully in democratic and civil life, due to poverty, lack of basic competencies and learning opportunities, or as a result of discrimination'.

\section{Economy, healthcare and social effects of economic crisis in Greece}

According to the latest available data published by the Hellenic Statistical Service (ELSTAT 2014) GDP declined at current prices from $€ 233.2$ billion in 2008 to $€ 193.7$ billion in 2012 . The negative effects can also be observed at the societal level, as all social indicators have deteriorated (ELSTAT 2014) as well. The economic crisis in Greece has unavoidably affected the health sector. With total expenditure close to 10\% of GDP in 2008 and 2009, health was a major contributor to both the deficit and the public debt. The fiscal crisis has led to a decrease in health spending, while the GDP is constantly declining since 2009. Total health expenditure in Greece accounted for $€ 19.8$ billion (9.4\% of GDP) in 2011 slightly higher the average of $9.1 \%$ in Eurozone, but considerably reduced from $€ 20.8$ billion in 2010 and $€ 23.2$ billion (10\% of GDP) in 2009 (OECD 2013).

The NGOs providing healthcare services faced in 2011 and 2012 great problems because of these delays (varying from 8 to 15 months) and nowadays, they still face problems (delays vary from 4 to 9 months). In addition, a lot of private clinics face serious problems in 2014 (since the 
government reduced by $50 \%$ comparing to last year's EOPPY's ${ }^{1}$ ceiling to providers, the result is that from July 2014 the insured have to pay out of pocket by $100 \%$ when treated in private clinics). Debts of EOPYY to private clinics each month amounts to about 50 millions. According to the PanHellenic Union of Private Clinics, six private clinics suspended their operation within March, because of serious liquidity problems.

An increase in co-payments for pharmaceuticals for specific diseases also took place in 2013, including Alzheimer, Dementia, Epilepsy, Diabetes II (from 0 to 10\%), Coronary Heart Disease, Hyperlipidemia, Rheumatoid Arthritis and Psoriatic Arthritis, Chronic Obstructive Pulmonary Disease (COPD), Osteoporosis, Paget Disease, Crohn Disease and Liver Cirrhosis (from 10 to 25\%). Furthermore, in 2013 the total number of medicines for which a $25 \%$ cost-sharing arrangement was imposed has been increased. As a result of these increases, the average co-payment rate for medicines increased from $13.3 \%$ in the first and second month of 2012 to $18 \%$ in the corresponding period of 2013 while monthly expenditure for households was increased on average from $€ 36.3 \mathrm{mil}$. in 2012 to $€ 38.2 \mathrm{mil}$. in 2013 (for the same periods over the two years), despite the price reductions (Siskou et al. 2014 ).

In relation to self-reported health in Greece, a study combining two national cross-sectional surveys conducted in 2006 and 2011 found that the probability of reporting poor self-rated health is higher at times of economic crisis, especially for the vulnerable groups including older people, unemployed, pensioners, housewives and those suffering from chronic disease (Zavras et al. 2012). These results are confirmed by another study which using data from the European Union Statistics on Income and Living Conditions survey showed that trends in self-rated health in Greece worsened as a result of the recent financial crisis (Vandoros et al. 2013).

World Health Organization (WHO) notes that in many countries, the closing of mental hospitals has not been accompanied by the development of community services, leaving a service vacuum with persons not receiving

\footnotetext{
1 The National Organization for Health Care Services Provision
} 
any care (WHO 2007). In Greece the psychiatric sector has been in constant reform since 1990. Some psychiatric hospitals, such as the Psychiatric hospitals of Athens 'Dafni', of Corfu and Crete (Chania) have been closed and a certain number of intermediate structures such as community mental health centres (about 45) have been created before and during the economic crisis. Nevertheless, the closure of specialized hospitals and the creation of community mental health centres or psychiatry clinics in general hospitals are, unfortunately, not accompanied by a systemic vision of the mental health system. During the crisis, NGOs, have developed 220 units (30\% of all mental health units), which covers $50 \%$ of the beds of the deinstitutionalization programme. These NGOs were the first victims of the crisis: $50 \%$ of their funding was cut leading many of them to default on their operational and payroll expenses for more than six months (Zafiropoulou et al. 2014)

The SILC conducted on an annual basis, provides information on the proportion of people reporting having some unmet needs for medical examination for different reasons. Table 1 summarizes the situation in Greece.

Table 1. Self-reported unmet needs for medical examination in Greece (too expensive or too far or extended waiting lists) from 2008 to 2012

\begin{tabular}{|l|c|c|c|c|c|}
\hline & 2008 & 2009 & 2010 & 2011 & 2012 \\
\hline Total population & 5.4 & 5.5 & 5.5 & 7.5 & 8.0 \\
\hline \multicolumn{7}{|c|}{ By income quintile } \\
\hline $1^{\text {st }}$ quintile & 8.7 & 11.2 & 9.2 & 11.6 & 11.6 \\
\hline $2^{\text {nd }}$ quintile & 7.1 & 7.4 & 6.7 & 9.8 & 9.6 \\
\hline $3^{\text {rd }}$ quintile & 6.1 & 4.6 & 5.9 & 7.6 & 9.2 \\
\hline $4^{\text {th }}$ quintile & 3.4 & 2.7 & 3.2 & 4.8 & 4.7 \\
\hline $5^{\text {th }}$ quintile & 1.8 & 1.7 & 2.2 & 3.6 & 4.8 \\
\hline \multicolumn{7}{|c|}{ By labour status } \\
\hline Employed & 3.3 & 2.8 & 3.1 & 4.7 & 5.6 \\
\hline Unemployed & 8.6 & 7.5 & 9.4 & 11.3 & 10.8 \\
\hline Retired & 7.6 & 7.8 & 7.3 & 10.2 & 9.4 \\
\hline Other inactive & 5.9 & 7.3 & 6.3 & 6.9 & 8.1 \\
\hline
\end{tabular}

Source: Eurostat 2013 


\section{A problem of access to healthcare services for emerging vulnerable groups}

According to ontology's results the majority of NGOs' representatives identified the same new groups of vulnerable persons concerning access to healthcare services:

- retired persons with small pensions and healthcare problems (according to $80 \%$ of respondents);

- disabled persons (according to $57 \%$ of respondents);

- persons with chronic health conditions (according to $45 \%$ of respondents) and

- cancer patients (according to 38\% of respondents).

The paradox for the elderly: the less poverty stricken and the most excluded of healthcare services age group

In 2011, 34.6\% of the Greek population was in risk of poverty and social exclusion. This is more than 10 percentage points higher than the EU-15 average. We observe that according to official statistics the poverty rates of the elderly were initially much higher than all other age groups $(29.4 \%$ in 2003), however since the mid-2000s the elderly's position improved over time, reaching $22.3 \%$ in 2008. Between 2009 and 2011 their poverty rates increased from $21.4 \%$ to $23.6 \%$, but then declined substantially to $17.2 \%$, making this age group the less poverty stricken age group. In fact, it is the only age group for which the relative poverty fell, as low pensions were cut less compared to wages. However, while the elderly's lot in 2012 seems to have improved in relative terms and it is seemingly less affected by monetary poverty, paradoxically the elderly's exclusion from access to healthcare services and medicines, which is certainly a significant measure of elderly individuals' well-being. EU silk data reflecting the same phenomenon notes that the self reported unmet needs for medical examination (because of the cost of services were too expensive, of their 
geographic coverage and the extended waiting lists) for retired people rose, from $7.6 \%$ in 2008 to $9.4 \%$ in 2012 .

In addition, according to Eurostat data from 2000 to 2008 the elderly traditionally suffered substantially higher poverty rates than other age groups and therefore found themselves steadily above the average poverty rates for the entire population. Despite this dramatic situation, no strategic health plan exists for the elderly in Greece. The reduction in pensions has reduced the ability of the elderly to access healthcare services. Increased cofinancing for medication and the closure of certain local health structures have aggravated this situation. Difficulties arise when follow-ups or further medical examinations out of the hospital are required at a later stage. In these cases, the elderly often drop out of treatments or miss follow-up consultations. The following text passages correspond to the opinion of NGOs representatives collected during FragMex and Eurofound research:

'It is assumed that there is no access at this time, for a huge part of the population, to health... to primary health care, which are the simplest things. This part of exclusion is not completely social, but when one has no access to health services, in fact, he is isolated from society.' (General Secretary to the Board of the organization FRONTIZO$\Phi P O N T I Z \Omega)$

'When someone doesn't have health care insurance, it is very difficult to overcome an emerging problem... the best you can do is go directly to a hospital and then the hospital will tell you to sign that you do not have money, you do not have the resources and the amount you owe to the hospital will be sent to the tax office.' (Social worker of ALMA ZOIS- A $\Lambda$ MA Z $\Omega H \Sigma$ )

'As I have said before... and... uh... unimpeded access to health care and welfare services... This... I really thought this would never happen... in such a violent (!) manner and no one would react... that people would consider all this normal.' (Coordinator of programs PRAXIS$\Pi \mathrm{PA} \Xi \mathrm{I} \Sigma)$

In the majority of cases austerity has led NGOs to put more emphasis on free services provided for the elderly. The activities of Doctors of the World demonstrate the large scale of the problem. Indeed, increased demand by the Greek population has led the organization to develop a 
number of activities and programs, intended to provide the local population not only with health services, but also with a wider range of social care services (dormitory for homeless people, food distribution, elderly care program, etc.), which are not typically part of the Doctors of the World activities. In the context of a new (2012) elderly care program, which includes other services, such as food provision, the organization provides primary healthcare and medicinal coverage to the elderly through polyclinics and house calls and performs a vaccination program during the months of October and November. It is important to note that in Perama, where the Doctors of the World run their elderly care program, the average income of the people participating in the program is only 213 Euros per month, while before the economic recession their average income was triple that figure. Also because of high unemployment, many younger people return to live home with their elderly parents, which on the one hand further reduces their income and thus their ability to pay for healthcare and on the other hand increases their anxiety problems.

'What we see is obvious, I think it's a common finding that the income of such persons, of elderly or of people with disabilities has been reduced. So the point is that these people need a lot of support, because beyond their problem they have to support their children and grandchildren.' (General Secretary to the Board of organization FRONTIZO- ФPONTIZ $\Omega$ )

'The point is, that the elderly cannot support future generations; this constitutes a very serious issue. It's the reason why disorders, dementia, depression and anxiety have increased at this age.' (General Secretary to the Board of organization FRONTIZO- $\Phi P O N T I Z \Omega$ )

\section{The problematic situation of those most dependent of the healthcare sector:} people with chronic health conditions, disabled people and cancer patients

The crisis has also affected the already precarious economic situation of chronically ill people. As a result of this situation, visits of people with chronic diseases (especially diabetes) have increased to NGOs and other 
social clinics. According to Doctors of the World, visits by chronically ill patients to their polyclinics have increased by $23 \%$, mainly in order to receive their medication since, due to the increase in their co-financing for medicines, they are unable to afford them.

According to results from a survey conducted by the National School of Public Health from September 2012 to February 2013, 64\% of respondents $(\mathrm{N}=1,496)$ reported problems in accessing a physician or a primary care unit due to economic restrictions and $60 \%$ of them due to long waiting lists. Access to health care services was associated with the socioeconomic status. Thus, chronically ill patients of higher income and educational level were less likely to face this kind of accessibility problems (National School of Public Health 2013).

Cancer patients, as well, represent one of the most vulnerable groups as all changes described above are particularly striking in cancer care, with its lengthy and expensive treatments. Cancer patients are one of the patient groups worst affected by the health care budget cuts and are facing serious problems during the economic crisis regarding waiting times and access to appropriate medicines (Apostolidis 2013). During the last two years, delays and discomfort have been reported by patient organizations in receiving their drugs.

According to the respondents, the disabled population is the one who faces both healthcare and social exclusion problems:

'There was racism and marginalization because he [a disabled person] is a man with special needs and disabilities. So, even only this sets him aside a society. I think the Greek society is conservative. He was already marginalized, now he is even further aside. So there are no opportunities, let alone for a disabled... what can we claim for him?...' (President of THALASSAIMIA- $\Theta A \Lambda A \Sigma \Sigma$ AIMIA)

'There are some benefits given, there is the legislation to protect us, but if you move around Athens and other Greek cities, the ramps for uh uh... wheelchair users, the majority of them, are dangerous and inappropriate. Which means, very simply, that a wheelchair user cannot move autonomously. This is so, unlike in other foreign cities 
where they come out of their house and circulate freely.' (General Secretary of PARAPLIGIKOI- ПАРАП ННГНКОI)

'There are both programs and global social security, but there is no national plan. We have to make policies for people with disabilities by category and according to the needs of each disability. In 2012 the Greek Parliament ratified the UN Convention for people with disabilities and this law was adopted, but it remained on paper only.' (General Secretary of PARAPLIGIKOI- ПАРАПАНГНКОI)

\section{Greek citizens: the 'new excluded' of the system}

A study conducted by the Médecins du Monde in order to investigate the situation of the persons who could not access healthcare professionals in the mainstream system (Chauvin and Simonnot 2013) in Europe in 2012, revealed that Greek citizens constitute the new 'excluded' of the healthcare sector. Data was collected in 14 cities (four of which were Greek) located in 7 European countries and the sample consisted of 8,412 patients (1,505 of which were residents in Greece). The survey was based on samples of Médecins du Monde patients consisting of natives and migrants. Their polyclinics in Greece deliver healthcare to the most vulnerable groups (migrants, poor, unemployed etc.) According to the study, it is particularly noteworthy that approximately half $(49.3 \%)$ of the patients examined in the four Greek clinics in 2012 were Greek nationals. In Perama (wider Athens area) this figure reaches $88 \%$, in Thessaloniki $52.1 \%$, in Athens $11.8 \%$ and in Patras 5.8\%. In the study, it was mentioned that the high rate of Greek nationals seeking healthcare from humanitarian NGOs is a dramatic consequence of the severe crisis which has hit Greece over the last two years. It is unique among the clinics that participated in the data collection: in the other countries, this proportion was less than 5\% (except in Munich where $12 \%$ of patients were nationals) and was almost zero in Amsterdam, Antwerp, Brussels and London' (Chauvin and Simonnot 2013).

'Thousands of poor people with no access to health care (migrants, but 
unfortunately also many Greek citizens) sought free primary health care. Consequently, MDM had run out of medicines'. (Head of unit of MEDECINS DU MONDE)

Traditionally, the NGOs work was focused on the poor classes. Nowadays, more persons are considered to be excluded of society and thus of healthcare services, such as single mothers, homeless or the elderly. They are either Greek citizens either highly integrated migrants. Consequently, this considerable change of the profile of people approaching Greek healthcare NGOs for assistance reveals that medium class is harshly affected by crisis:

'Now, the Greek society has to deal with unemployment, inability of young people to find work and redundancy for those who are employed. Moreover, the minimum wages are too low, they do not cover the basic needs of the employee and in many cases he is forced to work uninsured.'(Director of MERIMNA- MEPIMNA)

'Our phone rings and a person says $<I$ am an uninsured cancer patient and I don't know where to go', because a person who is uninsured and diagnosed with breast cancer for example, cannot go to the doctor and tell him sive me chemotherapy); a chemotherapy costs 2000-3000 Euros and the patient must have 12 of them [...] it is not only a simple dermatologic problem, that I can go to the dermatologist for and even if I am not insured, I pay only 30 Euros and the problem is resolved.' (Representative of ALMA ZOIS- A $\Lambda$ MA Z $\Omega H \Sigma$ )

\section{The emerging civil society's alternative model in order to face the crisis}

\section{NGOs retaining access to healthcare}

Increased demand of the Greek population has led some NGOs to develop a number of activities and programs, intended to provide the local population not only with health services, but also with a wider range of social care services (dormitory for homeless people, food distribution, elderly care programme, etc.) which until recently were not typically part their activities. For example Médicins du Monde established two new polyclinics, one in 
Perama, a low-income district in the area of Athens, in 2009 and one in the city of Patras in 2012 as a response to crisis. Additionally, a vaccination programme was introduced for children of Greek uninsured citizens. In 2012, only in the area of Perama 880 children were vaccinated. The programme takes place not only in Athens, or the other cities where the organization runs polyclinics, but also, through the mobile medical units of the organization, vaccination has also taken place in at least 30 isolated villages and islands. At the same time, the organization continues the vaccination of immigrants and other vulnerable groups, such as the Roma.

Generally, NGOs face the increasing demand and the deteriorating public social system through their community social and healthcare services and other unofficial networks of professionals and volunteers. It's worthy to note that they contribute significantly just to retaining access and not to improving it, to a basic set of services.

According to interviewees' answers to the question 'Why are civil society organizations necessary today?' three aspects seem particularly dominant regarding their key role:

- a question of principles: NGOs appear as an alternative way to create new civil dynamics promoting self improvement and self esteem and challenging a passive world;

- citizens' empowerment: NGOs' routes include enhanced flexible relationships with public and private organizations and partnerships with social network hubs involving citizens in a dynamic and innovative system of empowerment. They appear as testers-catalysts of a more democratic society;

- State's substitute: Challenging the State's ability to build an effective State, to react to a crisis and to provide assistance to the population, NGOs are described as a substitute of the State:

'Public protection mechanisms and all those who would have to operate without the assistance of non-governmental organizations do not exist; and unfortunately NGOs have substituted the State, not only at national but also at local level. We pay benefits, nationally or locally, to people who unfortunately cannot have these benefits because there is no 
relevant budget.' (Coordinator of programs PRAXIS- ПPA $\Xi \mathrm{I} \Sigma$ )

'Today, especially today, they tend to replace the welfare State. If you ask me, personally, it is not good that we are compelled at this time to perform breast cancer checks in social healthcare organizations run by NGOs. Drugs are in shortage, we intervene in disability awareness because people do suffer... All right, I think we have to be here.' (Social worker of ALMA ZOIS- A $\Lambda$ MA Z $\Omega H \Sigma$ )

The figure 1 presents in details these three main categories summarizing the role of NGOs in times of crisis.

Figure 1. Perception of NGOs representatives of the role of their organization in times of crisis, in Greece

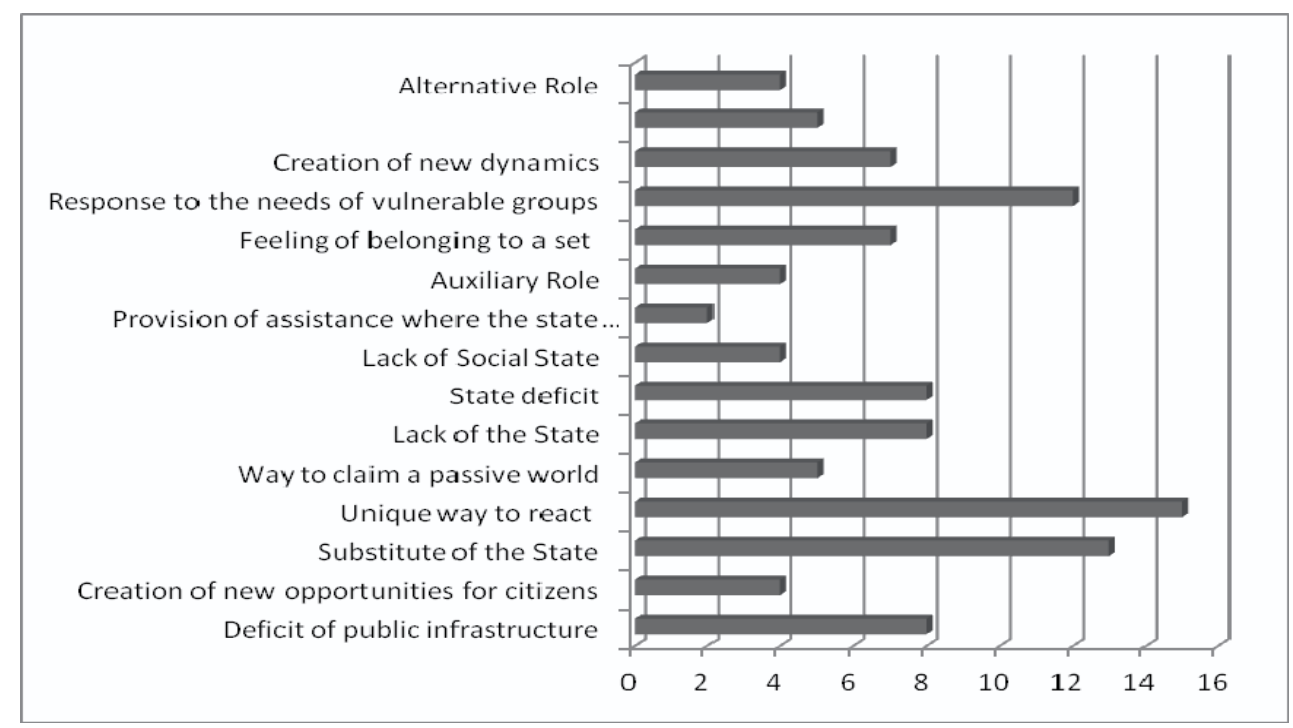

Source: Research project Eurofound and Fragmex (2014)

\section{From a traditional niche strategy to a new 'niche market' of ecclesiastic organizations}

The role of the church in response to the social and healthcare exclusion is crucial, especially during the crisis. Ecclesiastic organizations are considered as a new powerful stakeholder for many target groups of the crisis such as 
poor population and the elderly. Before the crisis, the activities of ecclesiastic organizations had features that appealed traditionally to a particular minority market subgroup i.e. their religious followers and referred only to social services. In order to face the impacts of the crisis, the Greek Orthodox Church has created market niches by identifying needs not addressed by other organizations or by the State and by offering even healthcare services to satisfy them. Particular emphasis has been given to the development of a dense network of mixed social and health welfare institutions and services. On 15 October 2009, the $4^{\text {th }}$ Session of the Holy Synod of Bishops of the Church was held on the establishment of the Ecclesiastical Relief Fund aiming to create a network of welfare projects. The language used in the Archbishop's public statements reveals this passage from a traditional niche strategy to a new niche market, as it became more focused on new groups of excluded populations. Care Homes and units for the chronically ill, social pharmacies, rehabilitation centres, centres for the elderly and more generally the distribution of free medicines, food and financial aids are some of the main activities of the Charity Fund of the Orthodox Church addressed to all vulnerable populations.

For the first time in the history of the Church, local and national synergies with other NGOs and informal networks have been created. The example of the Athens Medical Association demonstrates perfectly the emerging alliance between the Church and social and healthcare local or national organizations. The Athens Medical Association has entered into a cooperative scheme with the 'APOSTOLI-AПO $\Sigma \mathrm{TO} \Lambda \mathrm{H}^{\prime}$ (Mission) initiative of the Church of Greece and together they have created the Social Mission Infirmary, which operates since February 2012. 86\% of the people visiting the Social Mission Infirmary lost their social insurance during the years 2010, 2011 and 2012. Furthermore, 8\% of visitors are pregnant uninsured women facing high-risk pregnancies. The Infirmary provides primary healthcare for uninsured people in the area of Athens with 300 volunteers (doctors). There is also a social pharmacy operating at the premises, in order to cover the needs of the visiting population in medicines. Also the Infirmary cooperates 
with a network of psychiatrists, dentists and physiotherapists and also with a number of diagnostic centres. In cooperation with the Hellenic Association of Pharmaceutical Companies (SFEE), the Infirmary runs for the second year a campaign for child vaccination (8 out of 10 children visiting the centre benefit from this free service). $48 \%$ of the patients visiting the Infirmary are former self-employed people, who lost their insurance because of debts either to their insurance fund or the tax authorities. During 2013 both the Athens Medical Association and the Orthodox Church managed to collect a lot of medical material and pass it on to hospitals and local doctors' offices in remote areas of the periphery.

Another initiative of the Church and the Athens Medical Organization in cooperation with a national TV station has been to collect 650,000 medication items, allowing the establishment of social pharmacies throughout the country and directing 380,000 of them to local municipalities, local churches and various foundations. With the help of doctors and microbiological laboratories this initiative is able to offer every month for free blood tests and imaging exams to 80 patients with urgent and serious problems.

\section{Conclusions}

The alternative model of civil society's empowerment has not only become one of the most visible symptoms of the crisis but presents, as well, a conceptual construct that attempts to place citizens' synergies in a central place, in a space that emphasizes inter-relationships too often ignored by policymakers. Civil society's initiatives are the live example of its ability to understand the gaps and to propose innovative actions which, with the support of the local society or a local institution, can develop actions to retain the quality of access on healthcare services. For the first time in the Greek island of Kos has been created an organized and institutionally established core of volunteer citizens that will gradually include everyone who wishes to develop cooperative social actions which do not intend to 
gain health. 'We claim and prepare to take our share of responsibility by creating the right conditions for a public health system controlled by citizens and offered without profit to our own citizens with the participation of local doctors.' claims the mayor of the city.

In addition, NGOs (through their community clinics and pharmacies) and other unofficial networks of health professionals and volunteers helping poor and uninsured patients, have been associated in a network of around 40 community clinics. This informal healthcare network operates across Greece providing mostly primary health services and medications free of charge to people not able or not eligible to use the public services. The Metropolitan Community Clinic at Helliniko is another illustrative example, 'having offered services to more than 20.000 people since December 2011 when it was established in a volunteer basis as a response to a society operating in austerity and difficulty' (Economou et al. 2014, 112). All these emergent initiatives prepare the ground creating a 'new model' of citizens' empowerment and of public policy. And this may be our more optimistic future...

\section{Acknowledgments}

The research described in this paper has been funded by two European projects. Hellenic Open University's (http://www.eap.gr) project FRAGMEX (ГГЕT GER_2365) (2013-2015) 'Fragmentation and Exclusion: Understanding and Overcoming the multiple impacts of European crisis', which is co-financed by the European Union (European Regional Development Fund) and Greek national founds through the Operational Program of Competitiveness and entrepreneurship (OPC II). The Eurofound's country report (2013-2014) written within a contract of ELIAMEP-Crisis Observatory (http://crisisobs.eu/) with Eurofound, as input for Eurofound's Research Report on 'Access to healthcare in times of crisis', available at http://www.eurofound.europa.eu/areas/health/ healthcareservices.htm. Opinions expressed are those of the author only. Special thanks to Costas Catelas. 


\section{References}

Apostolidis, Kathi. 2013. "Access to Medicines in Greece - A patient view from Greece." Patient View Quarterly June issue: 6.

Byrne, David. 1999. Social Exclusion. Oxford: Oxford University Press.

Chauvin, Pierre and Nathalie Simonnot. 2013. Access to healthcare of excluded people in 14 cities of 7 European countries. Final report on social and medical data collected in 2012. Paris: Médecins du Monde/Doctors of the World International Network.

Church of Greece. 2009. "Fourth Session of the Holy Synod of Bishops of the Church of Greece". Press release, 15.10.2009. Available at http://www.ecclesia.gr/greek/holysynod/holysynod.asp?archive= yes\&what_sub=d_typou\&etos=2009\&id=1116 (accessed: November 22, 2014) [in Greek].

Economou, Charalampos, Daphne Kaitelidou, Dimitris Katsikas, Olga Siskou, and Maria Zafiropoulou. 2014. "Impacts of the economic crisis on access to healthcare services in Greece with a focus on the vulnerable groups of the population." Social Cohesion and Development 9(2): 99-115.

ELSTAT. 2014. Living conditions in Greece. November 7, 2014. Athens.

Eurofound. 2014. Access to healthcare in times of crisis. Luxembourg: Publications Office of the European Union.

European Parliament and Council of Europe. 2014. Social exclusion - a danger for Europe's democracies. Committee on Social Affairs, Health and Sustainable Development. Report, Doc. 13636. October 27, 2014.

Eurostat. 2013. http://epp.eurostat.ec.europa.eu/portal/page/portal/ health/health_care/data/database (accessed: November 22, 2014).

Fischer, Andrew M. 2011. "Reconceiving Social Exclusion." Brooks World Poverty Institute Working Paper No. 146.

Maslow, Abraham H. 1943. "A Theory of Human Motivation." Psychological Review 50(4): 370-396.

National School of Public Health. Department of Health Economics. 2013. Economic Crisis and Chronical Diseases. Available at: http://www. esdy.edu.gr/files/009_Oikonomikon_Ygeias/FINAL\%20DATA.pdf (accessed: November 11, 2013).

OECD. 2013. Health Data. Available at: http://stats.oecd.org/ index.aspx?DataSetCode=HEALTH_STAT (accessed: November 11, 2013).

Silver, Hilary. 1994. "Social Exclusion and Social Solidarity: Three Paradigms." International Labour Review 133 (5-6): 531-578. 
Siskou, Ch. Olga, Daphne Ch. Kaitelidou, Panagiota S. Litsa, Georgia S. Georgiadou, Helen A. Alexopoulou, Panagiotis G. Paterakis, Sotiria P. Argyri, and Lycourgos L. Liaropoulos. 2014. "Investigating the economic impacts of new public pharmaceutical policies in Greece: focusing on price reductions and cost sharing rates." Value in Health Regional Issues 4c: 107-114.

Vandoros, Sotiris, Philipp Hessel, Tiziana Leone, and Mauricio Avendano. 2013. "Have health trends worsened in Greece as a result of the financial crisis? A quasi-experimental approach." The European Journal of Public Health 23(5): 727-731.

WHO. 2007. Global Forum for Community Mental Health. Geneva, May, 3031, 2007.

Zafiropoulou, Maria, Daphne Kaitelidou, Olga Siskou, Dimitris Katsikas, and Charalampos Oikonomou. 2014. Impacts of the crisis on access to healthcare services: Country report on Greece. Internal Report for Eurofound.

Zavras, Dimitris, Vasiliki Tsiantou, Elpida Pavi, Katerina Mylona, and John Kyriopoulos. 2012. "Impact of economic crisis and other demographic and socio-economic factors on self-rated health in Greece." The European Journal of Public Health 22(2): 206-210. 